\title{
Mirroring Solar Radiation Emitting Heat Toward the Universe: Design, Production, and Preliminary Testing of a Metamaterial Based Daytime Passive Radiative Cooler
}

\author{
Anna Castaldo ${ }^{1, *(\mathbb{D})}$, Giuseppe Vitiello ${ }^{1}$, Emilia Gambale ${ }^{1}$, Michela Lanchi ${ }^{2}$, \\ Manuela Ferrara $^{3}$ (D) and Michele Zinzi ${ }^{4}$ (D) \\ 1 ENEA-TERIN-STSN-SCIS Portici, 80055 Naples, Italy; giuseppe.vitiello@enea.it (G.V.); \\ emilia.gambale@enea.it (E.G.) \\ 2 ENEA-TERIN-STSN-SCIS Casaccia, 00123 Rome, Italy; michela.lanchi@enea.it \\ 3 ENEA-TERIN-FSN-DIN Portici, 80055 Naples, Italy; manuela.ferrara@enea.it \\ 4 ENEA-TERIN-SEN Casaccia, 00123 Rome, Italy; michele.zinzi@enea.it \\ * Correspondence: anna.castaldo@enea.it; Tel.: +39-(0)81-772-3358
}

Received: 16 June 2020; Accepted: 10 August 2020; Published: 13 August 2020

\begin{abstract}
A radiative cooling device, based on a metamaterial able to mirror solar radiation and emit heat toward the universe by the transparency window of the atmosphere $(8-13 \mu \mathrm{m})$, reaching and maintaining temperatures below ambient air, without any electricity input (passive), could have a significant impact on energy consumption of buildings and positive effects on the global warming prevention. A similar device is expected to properly work if exposed to the nocturnal sky, but during the daytime, its efficacy could be affected by its own heating under direct sunlight. In scientific literature, there are only few evidences of lab scale devices, acting as passive radiative cooling at daytime, and remaining few degrees below ambient air. This work describes the proof of concept of a daytime passive radiative cooler, entirely developed in ENEA labs, capable to reach well $12{ }^{\circ} \mathrm{C}$ under ambient temperature. In particular, the prototypal device is an acrylic box case, filled with noble gas, whose top face is a metamaterial deposited on a metal substrate covered with a transparent polymeric film. The metamaterial here tested, obtained by means of a semi-empirical approach, is a spectrally selective coating based on low cost materials, deposited as thin films by sputtering on the metallic substrate, that emits selectively in the 8-13 $\mu \mathrm{m}$ region, reflecting elsewhere UV_VIS_NIR_IR electromagnetic radiation. The prototype during the daytime sky could reach temperatures well beyond ambient temperature. However, the proof of concept experiment performed in a bright clear June day has evidenced some limitations. A critical analysis of the obtained experimental results has done, in order to individuate design revisions for the device and to identify future metamaterial improvements.
\end{abstract}

Keywords: cool roof; passive radiative cooling; metamaterials; prototype

\section{Introduction}

The average ambient air temperature has raised by about $0.12{ }^{\circ} \mathrm{C}$, per decade, since 1951 because of climate change [1]. This trend has been emphasized at a local scale by the Urban Heat Island (UHI) effect, defined as the increase of urban temperature compared to that of the countryside surrounding the city, caused by the synergic action of urban sprawl and global warming [2-4].

Aligned with the ambient temperature increase, a relevant rise of the electricity consumption can be expected in the future [5]. Wenz et al. [6] demonstrated that electricity uses in Southern European 
countries exceeded by $7 \%$ that of Northern European ones, due to the occurrence of higher temperature levels often concentrated in short periods, attributable to building space cooling [7]. Implications also regard thermal comfort and quality of life, especially for low-income people [8].

The role of proper building materials in the mitigation strategy to fight against overheating is widely documented in the literature [9-11]. The so-called cool materials, which are characterized by high solar reflectance and high thermal emissivity, can limit the temperature rise of urban fabrics. Several technologies emerged in the past years to enhance the building energy performance and architectural integration: spectrally selective [12], fluorescent [13], dynamic [14] materials. Moreover, the production and characterization of super cool materials is documented in [15]; these materials remain below the ambient temperature under solar irradiation, thanks to extremely high emissivity and solar reflectance (both above 0.96/0.97).

In this perspective, potentialities of daytime radiative coolers are very high and, thus, they are gaining attention as ways to cool down buildings and cities. Benefits of nighttime radiative cooling have been documented in recent decades $[16,17]$, while daytime radiative cooling is an emerging technology, which has to face the challenging task of keeping the material surface well below the ambient temperature under solar irradiation [18]. Few materials can fulfill this objective thanks to very high reflectance in all the solar and in infrared range with exception of the atmosphere transparency window $(8-13 \mu \mathrm{m})$, which also corresponds to the peak thermal emission of bodies at ambient temperature [19]. These materials must have very high emissivity only in the latter range and are, thus, able to cool down radiating the heat in the outer space [20].

Despite significant progress in the field, daytime cooling technologies are still under study and development [21]. Recent advances in the electromagnetic field, related to nanotechnologies, have demonstrated to be promising for this specific application [19]. Essentially a photonic approach can modulate the emission and adsorption of electromagnetic radiations in specific ranges, to create one-dimensional (1D), 2D, and 3D metamaterials [22]. A first application of a photonic approach to obtain a device with a metamaterial able to reach $5{ }^{\circ} \mathrm{C}$ under ambient temperature during daytime has been reported by Raman and colleagues of the Stanford team, in 2014 [23]. Their proposed metamaterial is an alternating dielectric layers stack, obtained based on hafnium and silicon oxides deposited by evaporation. Other solutions based on metamaterials or porous alumina were developed more recently [24-26].

In consideration of the possible closure of the atmosphere transmittance window in presence of high humidity (water vapor blocks infrared radiation), many studies have been done on the evaluation of the influence of emission selectivity [27]. For example, in determined environmental conditions, reflecting only solar range and emitting elsewhere could result simplest and cheaper [28]. Moreover, polymeric formulations containing silica nano-spheres to be coupled with metallic reflective layers [29] have been proposed and compared with more sophisticated photonic metamaterials.

Starting from a multi-year experience in the development of spectrally selective coatings for receiver tubes in solar thermodynamic field [30], the authors have recently started an experimental activity focused on the development of simple, low cost, scalable coatings for daytime radiative cooling to be integrated in buildings fabrics or cooling system components. The aim of this work is to contribute to the advancement of knowledge and current state of art and research on this field, both in terms of new materials development and prototypal device fabrication, highlighting the following aspects:

- design and fabrication of new metamaterials on different substrates, pursuing a photonic approach similar to that reported from Raman and colleagues, in terms of reflectance higher than $95 \%$ in all solar spectral range, and selective emission only in 8-13 micron, but with cheaper materials and utilizing a different deposition process in spite of evaporation, as the low cost and scalable sputtering deposition;

- realization of a daytime radiative cooling prototypal device, for individuating possible applications and testing cool metamaterial and/or other similarly produced materials, which, taking into right account different contribution to heat transfer (conduction, convection, radiation, etc.), 
can maximize the optical performance of selective emission in 8-13 micron and reflective behavior in all wavelength range, working as heat exchanger if deposited onto metallic substrates.

Proof of concept (on technological scale) of the use of metamaterials here developed to reach a temperature well below ambient air during daytime.

Objective of the present study is the design and preparation of a daytime radiative cooler, characterized by an extremely high reflectance in all wavelengths except in the atmospheric transparency window (8-13 micron); thus, able to remain well below ambient temperature under solar irradiation. The use of cheaper materials and the sputtering deposition process, instead of evaporation, may lead to lower costs compared to similar developed solution

In particular, the proof of concept of the daytime passive radiative cooler device has been performed either protecting it by a transparent case, either directly exposing it to the outdoor environment, aiming at assessing the surface temperature drop potentialities in the Mediterranean climate and the options to implement low cost solutions.

In the following sections, the design and manufacturing of the prototype, the design and manufacturing of metamaterials, the characterization of chemical-physical and optical properties of the metamaterial, the testing on field of the prototype will be described.

\section{Materials and Methods}

The present daytime cooling prototypal device consists of a metamaterial deposited on a metallic substrate, directly exposed to the outdoor environment, or protected by a dedicated transparent case filled with a noble gas. Possible applications are: i) coupling with a cooling system, whose pipes run below the radiator (active/hybrid mode); ii) directly integrated in the building envelope as radiative cooler (passive mode), iii) simply utilization to test new selective engineered materials.

The present study is limited to the surface temperature drop with respect to the ambient temperature, as the unique performance indicator. Next developments will include the cooling power as additional indicator, to compare the results versus the already developed research and technology in this regard.

\subsection{Design and Manufacturing of the Prototype}

The case prototype has been specifically designed for this activity, and entirely realized in ENEA labs. It is a rectangular box $500 \times 400 \times 115 \mathrm{~mm}$, made of acrylic sheets nominally $10 \mathrm{~mm}$ thick and filled with pure Krypton, to minimize heat convection. The total weight of the box is about $6 \mathrm{Kg}$.

The prototype has a $300 \times 200 \mathrm{~mm}$ exposed area and it consists of the following parts, as indicated in the left scheme in Figure 1:

- transparent cover, to insulate the metamaterial from wind and water condensation;

- base layer, made of the acrylic sheet with a layer of insulating polystyrene foam placed on, and where the passive radiative cooler plate is collocated. This suppresses the conductive heat gain from the back surface and side-walls;

- connector for the installed thermocouple, used to measure the surface temperature during the test;

- screws to fix the transparent cover onto the base;

- valve to inflate gas into the case;

- valve to exit gas from the case. 


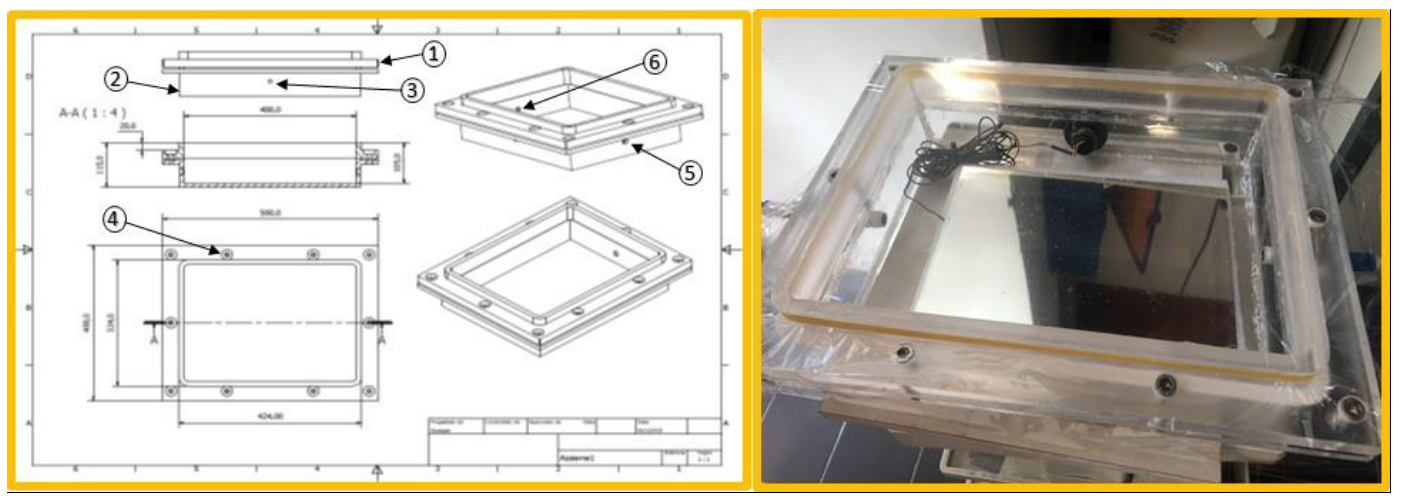

Figure 1. Cooler prototype scheme and photo.

\subsection{Design and Manufacturing of the Cool Metamaterial}

The radiative cooler consists of a substrate of aluminum of dimensions $300 \times 200 \times 1 \mathrm{~mm}$ coated with an engineered material, named in following sections cool metamaterial (CM) fabricated in ENEA labs by means of sputtering deposition technique.

In particular, the present $\mathrm{CM}$ has been obtained by means of a photonic approach (semi-empirical simulation method), already described in our previous works [31]. In more detail, a sequence of layers with specific thicknesses has been selected, based on our consolidated knowledge in the field of dielectric materials. Through the application of a commercial optical properties simulation software, Essential Macleod (a software for the design, analysis, simulation and troubleshooting of thin optical coatings), a first sequence of layers can be individuated starting from the data-base of the software and imposing desired transmittance or reflectance values to the entire structure. A second step consists in depositing each single layer on a glass substrate and in measuring the optical properties through spectrophotometric and ellipsometric experimental analysis. The last step consists in including the obtained experimental data in the software library, iterating simulation of the entire structure to obtain the theoretical optimal method (thickness of layers and their right sequence) to realize the CM with desired optical properties by means of sputtering. However, sequential deposition of different materials can create compatibilities issues that requires the addition of new layers or the modification of initially selected materials, iterating the previous steps until the optimization of the fabrication method. Finally, chemical-physical characterization of the experimental metamaterial can confirm the achievement of the desired optical properties or give suggestions on further iteration of the previous steps.

The CM selected for this work is part of a library of engineered metamaterials that can be optimized for different substrates. In particular, it consists of different layers of selected materials sputtered in the following conditions:

- $\quad$ silver (Ag) film, grown in DC sputtering mode, at Ar pressure of $0.1 \mathrm{~Pa}$ and with $1.65 \mathrm{~W} / \mathrm{cm}^{2}$ power density applied to the cathode;

- aluminum nitride (AlN) layers, grown at $\mathrm{Ar}+\mathrm{N}_{2}$ pressure of $1 \mathrm{~Pa}$ and with power density of $7.75 \mathrm{~W} / \mathrm{cm}^{2}$ applied to $\mathrm{Al}$ cathode;

- aluminum oxide $\left(\mathrm{Al}_{2} \mathrm{O}_{3}\right)$ layer, deposited at $\mathrm{Ar}+\mathrm{O}_{2}$ pressure of $1 \mathrm{~Pa}$ and with power density of $7.75 \mathrm{~W} / \mathrm{cm}^{2}$ supplied to $\mathrm{Al}$ cathode;

- $\quad$ silicon nitride $\left(\mathrm{SiN}_{\mathrm{x}}\right)$ films grown in a gas mixture of $\mathrm{Ar}+\mathrm{N}_{2}$ at different concentration and total pressure ranging from 0.7 to $1 \mathrm{~Pa}$. The Si target has been pretreated using an $\mathrm{Ar}+\mathrm{H}_{2}$ gas mixture to reduce the contamination on the $\mathrm{Si}$ target surface. As an example for $\mathrm{SiN}_{\mathrm{x}_{-}} 01$ and $\mathrm{SiN}_{\mathrm{x}_{-} 02}$ these experimental conditions have been applied:

- $\quad \mathrm{SiN}_{\mathrm{x} \_} 01$ medium frequency $200 \mathrm{~W}, 200 \mathrm{sccm} \mathrm{Ar}+, 30 \mathrm{sccm}$ of $\mathrm{N}_{2} 0.7 \mathrm{~Pa}$;

- $\mathrm{SiN}_{\mathrm{x} \_} 02$ medium frequency $1700 \mathrm{~W}, 200 \mathrm{sccm} \mathrm{Ar}+, 30 \mathrm{sccm}$ of $\mathrm{N}_{2} 1 \mathrm{~Pa}$. 
UV-VIS-NIR analysis has been performed using a double beam Perkin-Elmer model. Lambda 900 instrument, equipped with a $15 \mathrm{~cm}$ integrating sphere to measure global spectral reflectance and transmittance.

Ellipsometric analysis has been executed using a J.A. Woollam variable-angle spectroscopic instrument (Model VB-400) equipped with WVASE32 software.

Vibrational analysis of materials has been done using two Fourier Transform Infrared (FTIR), a Perkin Elmer for transmittance measurements, equipped with a Deuterated Triglycine Sulfate (DTGS) detector operating in the $400-10,000 \mathrm{~cm}^{-1}$ range and a Bruker Equinox with integrating sphere and MCT detector operating in the $760-8000 \mathrm{~cm}^{-1}$ range for diffuse reflectance measurements. The resolution has been comprised in the range 0.5 to $4 \mathrm{~cm}^{-1}$ for transmittance and $8 \mathrm{~cm}^{-1}$ for reflectance.

Substrates used for characterization purposes are $\mathrm{Si}$ (111), optical quality glass and stainless steel. As for the prototype fabrication, the selected substrate is aluminum, for a potential better integration in heat exchanger applications.

\subsection{Field Testing}

Experiments on field have been conducted in a sunny June 2019 day, comparing different temperatures read from thermocouples positioned as in Scheme 1 and recording data with a ThermoCamera. The thermocouples used to monitor $\mathrm{T}$ are Watlow shim style mod. $\mathrm{P} / \mathrm{N}$ 75XKSGA180B and model. P/N 70XKSGD180B with a stainless steel shim, which can also be placed between components for surface temperature measurement. The ThermoCamera is Fluke Ti27 IR FUSION TECHNOLOGY.
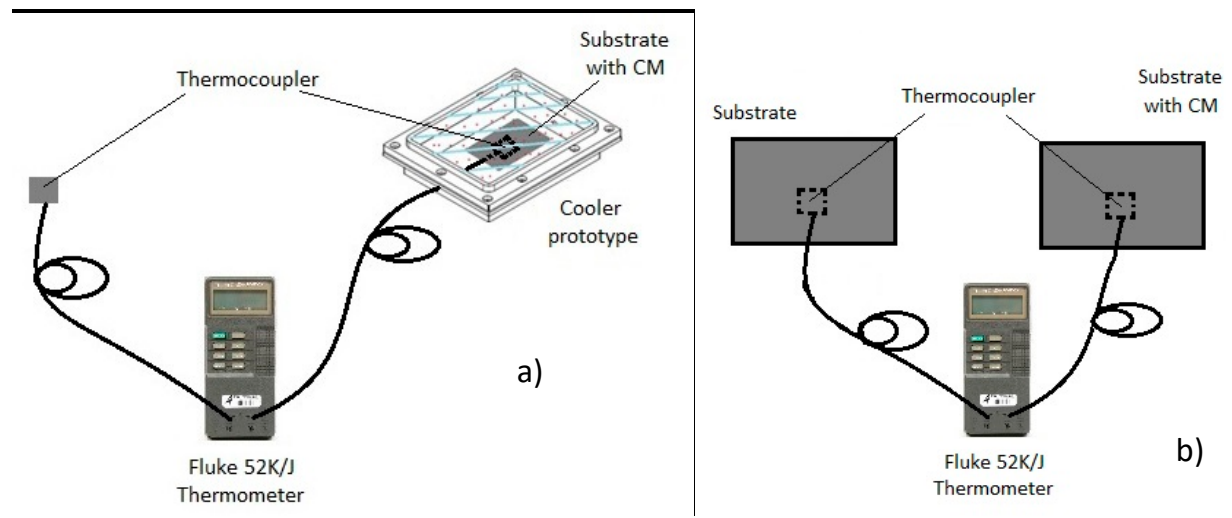

Scheme 1. Temperature test experiments on field.

The images are recorded, analyzed with the SmartView software, and compared with the data from the thermocouple, as reported in Figure 2.

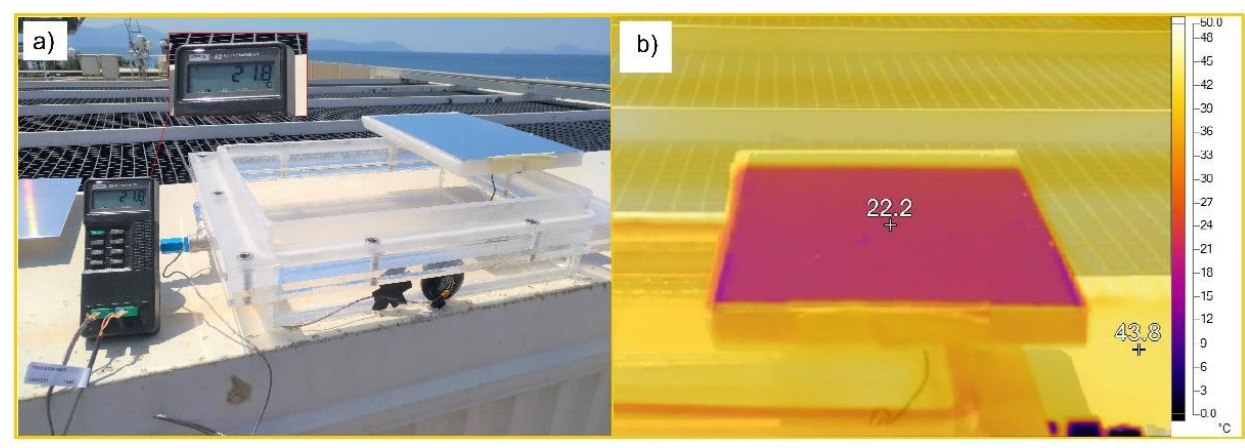

Figure 2. Thermocouple (a) and thermocamera (b) reading temperature comparison. 
This validation test can be useful to assess, in the temperature range under exam, an error, in the temperature measurement, of the order of $+/-0.5^{\circ} \mathrm{C}$.

The environmental average conditions of the day of the experiment are the following: wind speed $=3.11+/-0.08 \mathrm{~m} / \mathrm{s}$; wind direction $214+/-1^{\circ} 0^{\circ}=$ North; $\mathrm{T}=26.41+/-0.11^{\circ} \mathrm{C}$.

\section{Results}

The proof of concept of a passive daytime radiative cooling device, potentially integrable with a chiller or a fan coil, has required the following steps: 1) fabrication of the prototype case; 2) fabrication and characterization of the emissive metamaterial, $\mathrm{CM}$; 3) selection of cover polymeric material, which preserves optical properties of $\mathrm{CM}$; 4) field testing of the device operation as passive radiative cooler.

The design and realization of the prototype case is described in the previous paragraph and can be considered as a first important practical result.

The second step is the development of an engineered cool metamaterial, $\mathrm{CM}$, able to satisfy some stringent optical requirements (e.g., selective emissivity) as reported in Figure 3, and the deposition of it on an aluminum plate acting as heat exchanger, by means of reproducible, scalable and low cost processes.

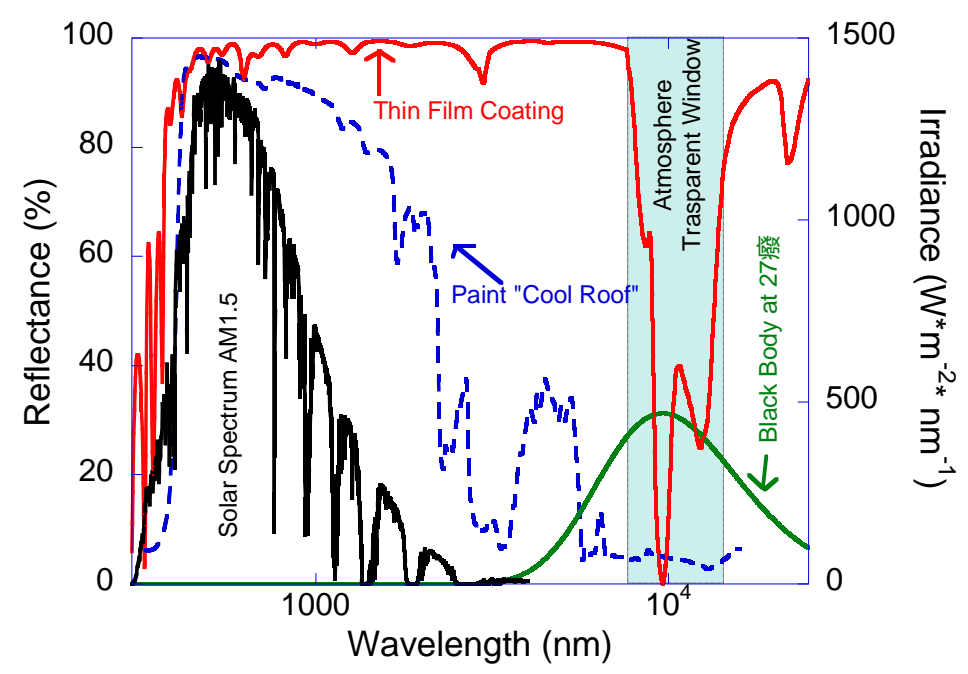

Figure 3. Reflectance spectra in the wavelength range 250 to $16,000 \mathrm{~nm}$ of simulated multilayered cool metamaterial (CM) (red line) in comparison to a simple cool roof paint (blue line), reported with Solar Spectrum AM1.5 irradiance (dark line) and black body irradiance at $27^{\circ} \mathrm{C}$ (green line).

$\mathrm{CM}$ has been obtained by means of a photonic approach (semi-empirical simulation method), already described in ENEA's previous works, and detailed in the above section. In particular, a sequence of layers with specific thicknesses has been selected, based on a consolidated knowledge in the field of dielectric materials, and the resulting metamaterial properties have been simulated in solar range using a commercial optical properties simulation software (McLeod), to grant an high reflectance in such spectral region.

The resulting $\mathrm{CM}$ consists of different layers of silver, aluminum, and silicon oxides and nitrides $\left(\mathrm{SiN}_{\mathrm{x}}, \mathrm{SiO}_{2}, \mathrm{Al}_{2} \mathrm{O}_{3}, \mathrm{AlN}\right)$, with variable thicknesses. Two main requirements have been considered for the material definition: 1) strong emissivity in 8-13 micron, 2) different adaptive template layers, tailored for all different substrates where the metamaterial has to be deposited, both for development/characterization purpose and for prototype plate fabrication. In Table 1, the main structure obtained is reported. 
Table 1. Cool metamaterial (CM) structure composition.

\begin{tabular}{cc}
\hline Layer Composition & Thickness [nm] \\
\hline $\mathrm{SiO}_{2}$ & 230 \\
\hline $\mathrm{SiN}_{\mathrm{x}}$ & 150 \\
\hline $\mathrm{SiO}_{2}$ & 230 \\
\hline $\mathrm{Al}_{2} \mathrm{O}_{3}$ & 150 \\
\hline $\mathrm{SiN}_{\mathrm{x}}$ & 100 \\
\hline $\mathrm{Al}_{2} \mathrm{O}_{3}$ & 360 \\
\hline $\mathrm{AlN}$ & 100 \\
\hline $\mathrm{Ag}$ & 200 \\
\hline $\mathrm{AlN}$ & 10 \\
\hline Substrate & $>1500$ \\
\hline
\end{tabular}

The silicon based layers mainly contributed to the IR emissivity in the 8-13 $\mu \mathrm{m}$ wavelengths range while the thinner alumina bottom layers deposited on $\mathrm{Ag}$ coated metallic substrate, work in maximizing $(>95 \%)$ solar reflection.

Once defined, the materials sequence and the thicknesses of each layer, a relevant effort has been spent to fabricate CM. In particular, the work consisted in a full process manufacturing optimization, firstly requiring the sputtering deposition and characterization of each single layer, and then the full coating sequential deposition.

For a comprehensive chemical-physical characterization, the $\mathrm{CM}$ has been deposited on different substrates (stainless steel, silicon, glass), and on aluminum foil of $10 \times 30 \mathrm{~cm}$. To cover metallic substrates with the reflective silver layer, which has the highest reflectance in solar range (400-2500 nm), it is preferable to use an adaptive layer because metallic substrates are (usually) covered with native oxides, whereas silver growth on oxides is difficult [32]. To this purpose the consolidated technology of sandwiching silver between aluminum nitride lavers [33] has been adopted; the first AlN layer has the function of barrier toward diffusion of stainless steel elements and silver template, while the second aluminum nitride layer is a barrier between silver and oxygen contained in alumina successive layer. Another kind of adaptive layer can be Tungsten alpha or other materials that can work as template for a $2 \mathrm{D}$ of the noble metal at low thickness.

Alumina last layer was deposited by means of reactive sputtering, from an aluminum target and an oxygen reactive gas in target saturation region.

The role of silicon nitride is crucial for granting high selective emissivity. Within the present work, $\mathrm{SiN}_{\mathrm{x}}$ was deposited by means of reactive sputtering in $\mathrm{N}_{2}$ and Argon atmosphere, working in transition region of the silicon target. It is typically very difficult to sputter crystalline $\mathrm{Si}_{3} \mathrm{~N}_{4}$ (bulk material). In order to obtain the simulated metamaterial formulation, two silicon nitrides, with $\mathrm{Si} / \mathrm{N}$ ratio $<1.3$, were produced and characterized. In Figure 4, refractive index of the two samples $\mathrm{SiN}_{\mathrm{x}} 01$ and $\mathrm{SiN}_{\mathrm{x}} 02$ are reported, to show how it is possible to act on optical properties of thin layers varying sputtering process parameters.

In Figure 5 is shown a comparison between infrared reflectance of $\mathrm{CM}$ simulated and $\mathrm{CM}$ deposited on aluminum plate.

In Figure 6, a comparison between CM FTIR reflectance of CM, as deposited on different substrates by means of the same sputtering process is reported. It is remarkable the high reflectance in a large part of infrared range ( $>95 \%$ from 2000 to $6000 \mathrm{~cm}^{-1}$ ) and the strong absorption (and, hence, emission) in $670-1300 \mathrm{~cm}^{-1}$. Only few differences between metamaterials, as grown on different substrates in infrared reflectance spectra, are detectable, because reflective behavior of such metamaterial in this range is heavily influenced by the $200 \mathrm{~nm}$ silver layer. The absorption band $\left(670-1300 \mathrm{~cm}^{-1}\right)$ is identical in all different samples. A difference can be detected in the hydrogen bonds absorption band 
around $3300 \mathrm{~cm}^{-1}$, lied to $-\mathrm{OH}$ groups and around $3600 \mathrm{~cm}^{-1}$ lied to $-\mathrm{NH}$ groups and influenced by water content.

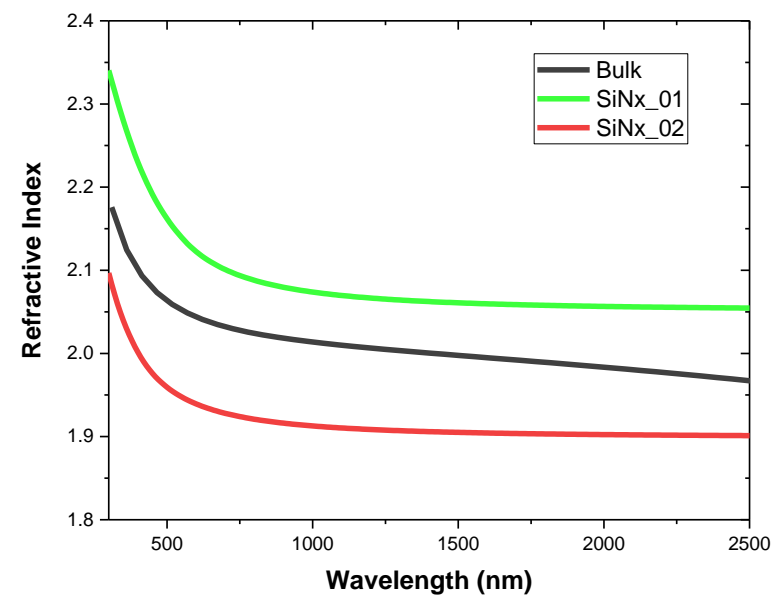

Figure 4. Refractive index of two silicon nitride thin layers compared to bulk one.

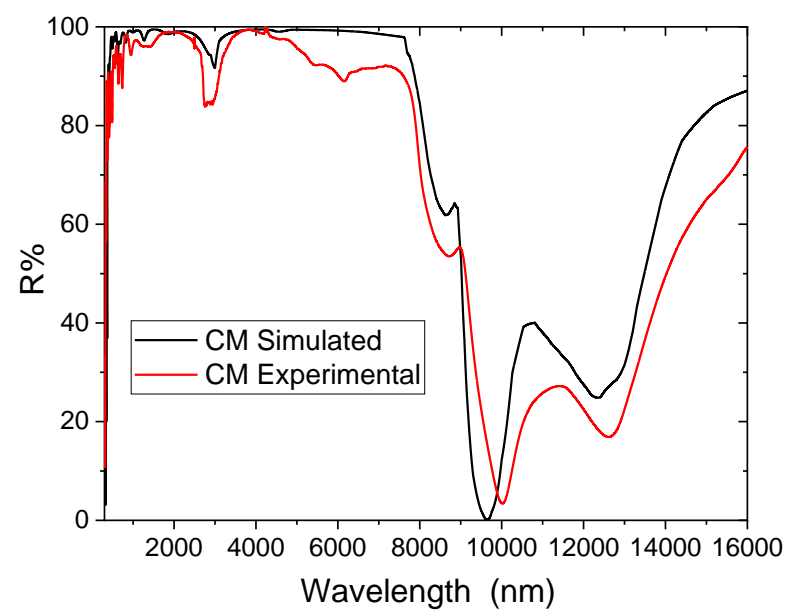

Figure 5. Infrared reflectance of CM simulated and experimental.

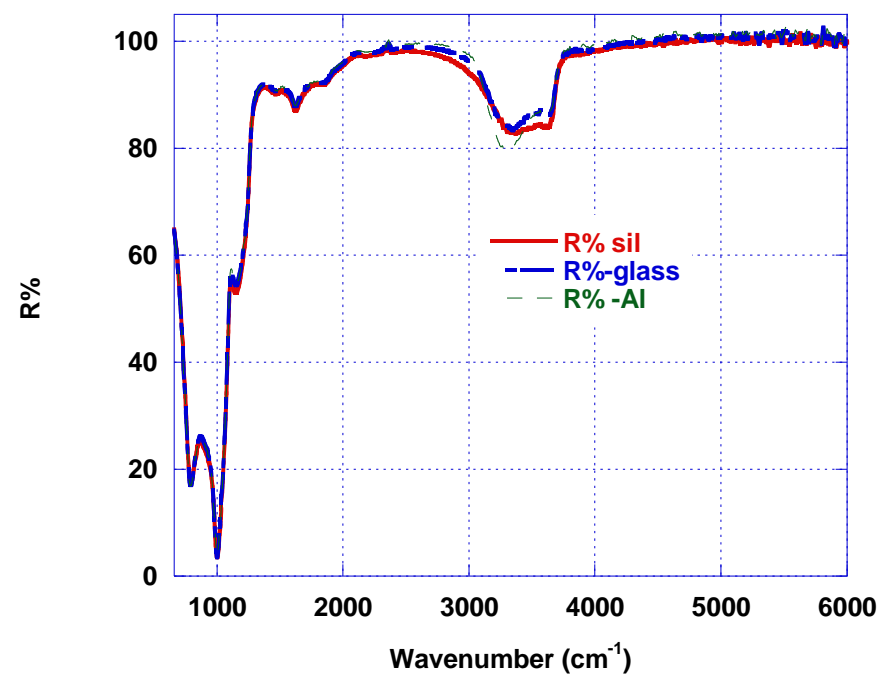

Figure 6. Infrared reflectance of CM deposited on different substrates: silicon (red line), glass (blue line), aluminum (green line). 
Apart from CM, a cover protecting the system from natural convection can also play an important role to optimize the performance of the radiative cooler. As above mentioned, for daytime application, it is fundamental to block convective heat gain, so that the cooling prototype's net radiated power is higher than the absorbed solar power and the device can yield a temperature below the ambient one. On the contrary, if the absorbed solar power is higher than the net radiated power, the device temperature becomes higher than the ambient air temperature. In this circumstance, the use of convective covers is undesirable, as natural convection can facilitate the release of heat from the cooling device. In the absence of direct solar radiation, convection covers can greatly improve the device performance in terms of radiative cooling.

To cover the box, protect the panel from air and wind, and suppress convective heat gain from the ambient, it is necessary to individuate a material with a high optical transmittance in 8-13 micron range, since differently this could reduce $\mathrm{CM}$ emissivity.

Moreover, the covering material has to be flexible and low cost. An organic material typically absorbs in such a region, but in literature it has been demonstrated that a thin film of pure polyethylene has a transmittance higher than $80 \%$ in the IR region 8-13 $\mu \mathrm{m}\left(769-1250 \mathrm{~cm}^{-1}\right)$, as reported in Figure $7 \mathrm{a}$ (book transmittance spectrum of polyethylene card). Different commercial samples of PE (of various origins and thicknesses) have been analyzed with other polymeric transparent materials (e.g., Fluon of different type, PE-PET of different thickness, PC, etc.). As an example, in Figure 7b, the FTIR Transmittance percentage (T\%) vs. wavenumber is reported for different selected samples (Fluon 250 (red line), PE film 6 micron thick (blue line), PET-PE 10 micron thick (green line), PE based freezer bag (dark line). Focusing on the interest region (Figure 7c), a 6-micron thick PE film cab be considered appropriate for the purposes of the present work. It is worth noticing that, in some commercial PE based polymers, a white pigment is present that interferes with optical behavior. In other terms, it is always advisable to verify, through FTIR analysis that the covering film is transparent in the specific interest region. Differently, the work to optimize metamaterial optical properties could be useless, since the effective front of the device is the polymer.

As shown, the selected PE film (6 micron thick) has the highest IR transmittance $(>80 \%)$ in the range 8-13 micron $\left(769-1250 \mathrm{~cm}^{-1}\right)$. As already mentioned, inside the rectangular box, the gap between stainless and polymeric cover has been filled with the noble gas Krypton, which has the lowest heat transfer coefficient, for reducing convection heat transfer.

\section{Verification of the Functionality of the Prototype}

The first experimental test on the prototype was conducted in June 2019, on a rooftop of the ENEA Portici Lab. In a preliminary phase of the test, the prototype was positioned on a rooftop, with thermocouples measuring metal radiator temperature and air temperature (as described in Scheme 1a): no temperature decrease of CM was observed, rather a little overheating. Subsequently, the polymeric cover was removed from the box, to avoid greenhouse effect, and the experiment was repeated on the metallic plate exposed directly to air, positioned on the casing but without cover. The plate temperature, measured on the underside of the heat exchanger, after 2 min went well below the air temperature, approximately of $12{ }^{\circ} \mathrm{C}$, even under direct solar irradiance staying unchanged for the duration of the test $(1 \mathrm{~h})$, as shown in Figure 8.

It can be hypothesized that the heat gain of the device, in the preliminary part of the test, was due to the direct sun irradiation of the box lateral sides. Sunshades should have been mounted around the periphery of the enclosure, to prevent the sun from heating up the box walls, causing greenhouse effect. Most probably, sunshades are not required for night operation of the device. The simple removal of the coverage was effective in reducing the device temperature. Since $\mathrm{CM}$ was directly exposed to air, the system did not perform at the best of its potentiality: indeed the presence of inert gas and PE film is expected to significantly contribute to reduce heat gain from ambient convection. 
(a)

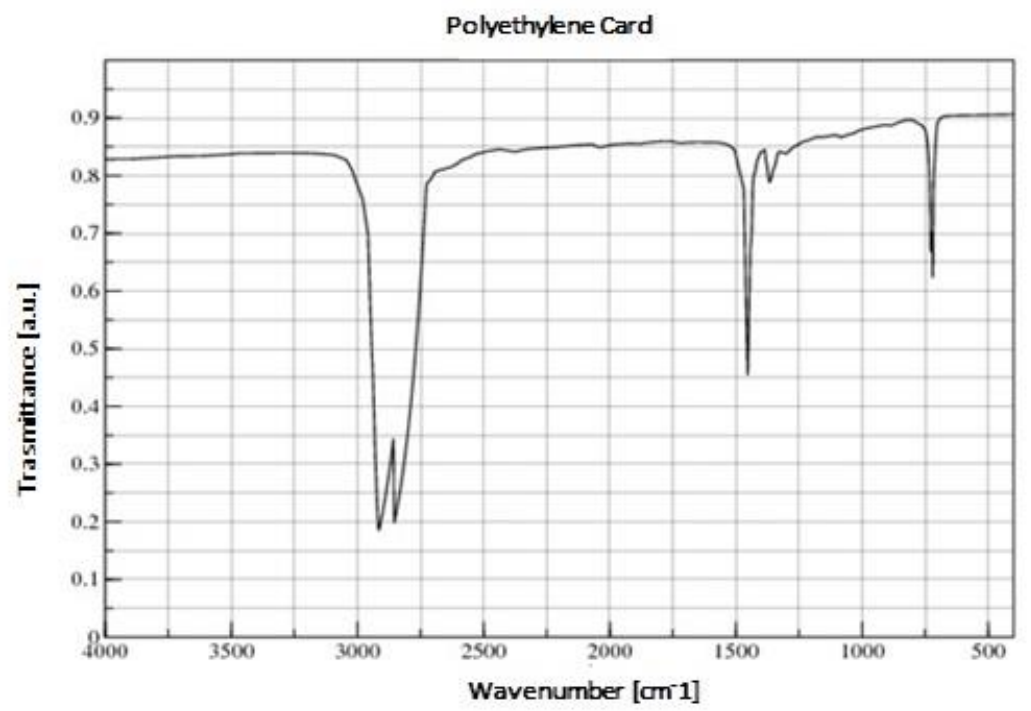

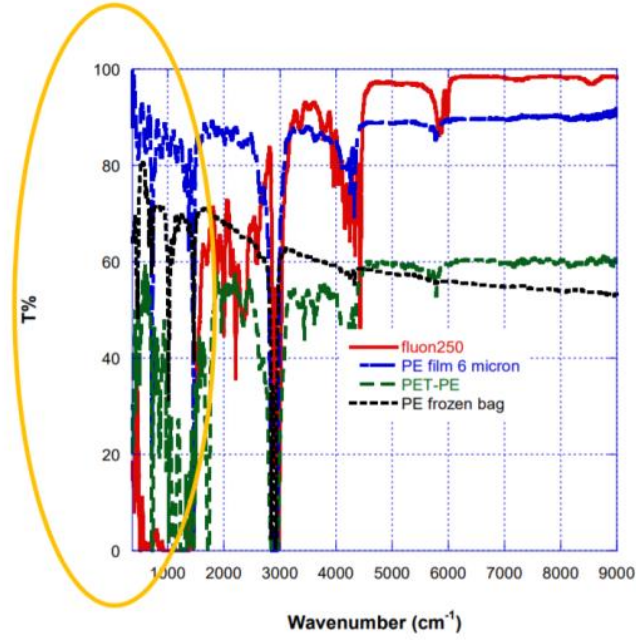

(b)

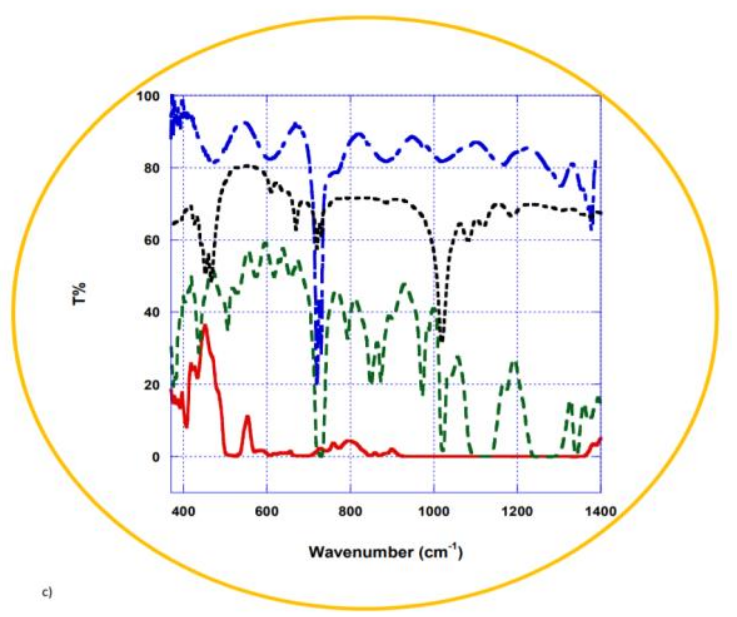

(c)

Figure 7. FTIR transmittance spectra of different polymeric thin films for selecting cover material. (a) Book spectrum of polyethylene card; (b) full range spectra of Fluon 250 (red line), PE film 6 micron thick (blue line), PET-PE (green line), PE based freezer bag (dark line). (c) Insert containing the interest region $\left(769-1250 \mathrm{~cm}^{-1}\right)$, where the most transparent polymer is the blue-one line.

Anyway, having extracted CM from the box (and consequently having only measured the CM thermal behavior and not the entire prototype performance), another shorter test was executed to confirm the metamaterial ability to reach temperatures lower than the ambient one. In particular, the temperature difference $(\Delta \mathrm{T})$ occurring between two metallic identical plates exposed to clear sky conditions, one of which covered with metamaterial, was measured positioning two thermocouples as represented in Scheme 1b. In Figure 9, the maximum temperature difference measured (a) and the temperature course (b) are reported. As shown in Figure 9, the CM was able to reach a temperature $12{ }^{\circ} \mathrm{C}$ lower than its substrate.

The CM exposed to the air after the test started to partly peel off from the metallic slab substrate edges. The peeling process that initially started in the edges region (Figure 10b), after 1 month of air exposure (Figure 10a), appeared uniform on the entire slab. Pink regions, entirely delaminated from 
substrate, are visible in Figure 10a. Such behavior is not detectable in samples deposited on different substrates (produced for analytical purposes).

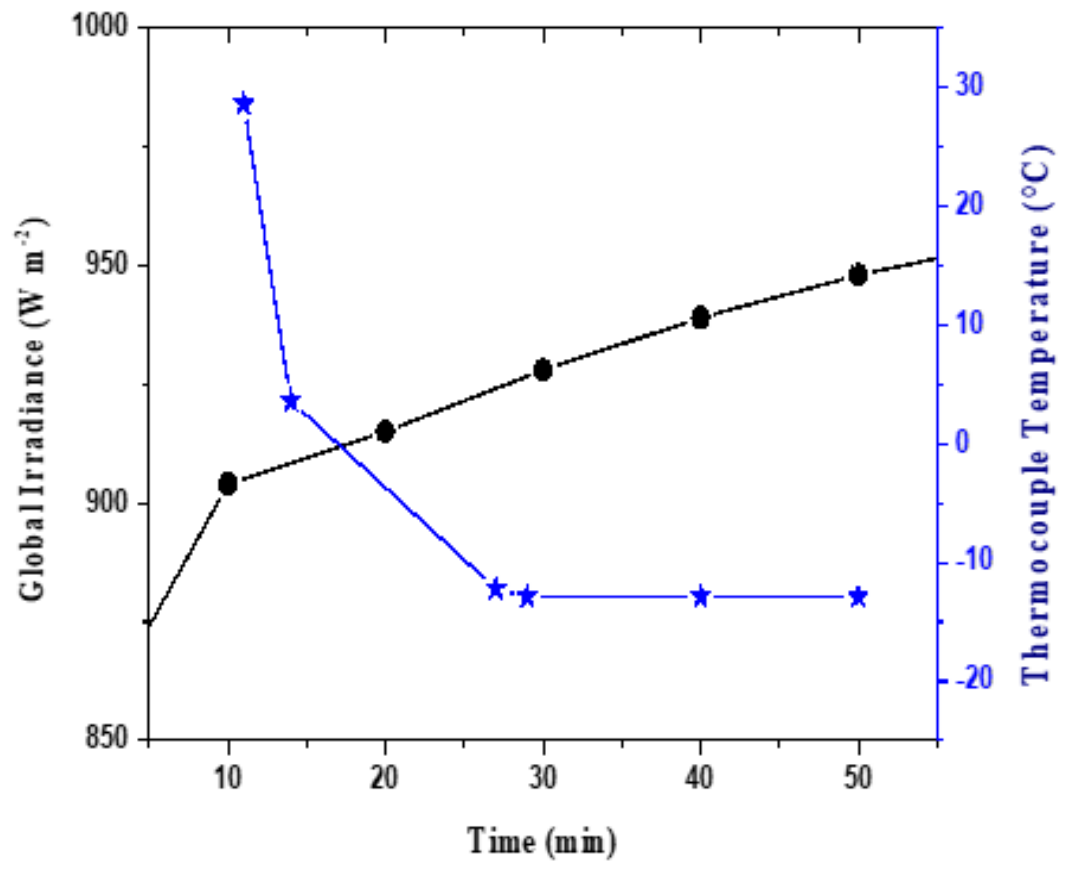

Figure 8. Experimental characterization of the radiative cooler prototype on the roof: first experimental test.

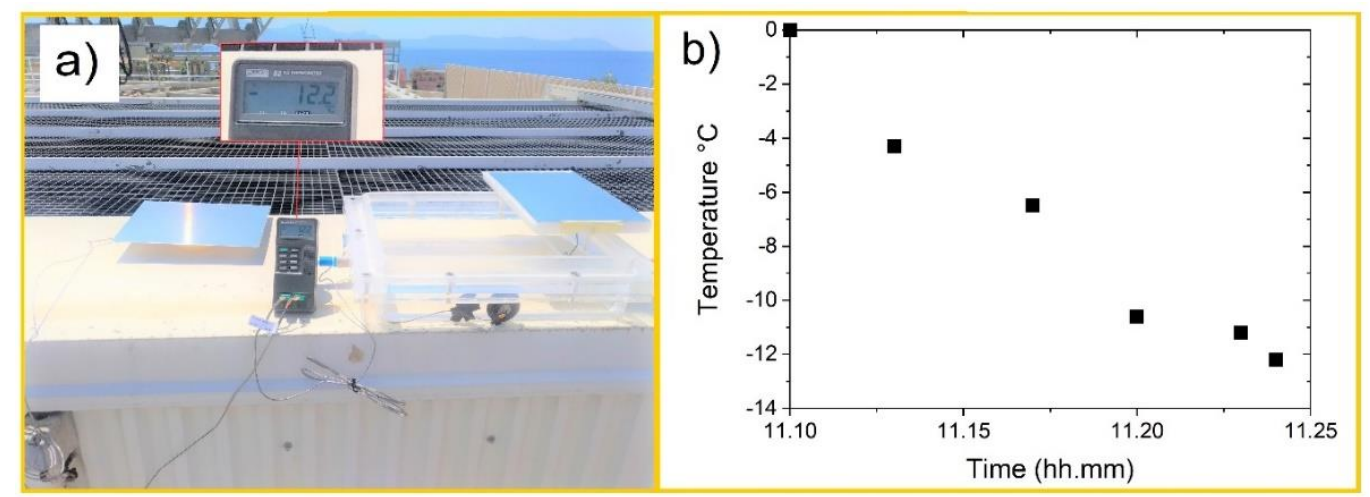

Figure 9. Comparative temperature test between $\mathrm{CM}$ and identical plate without coating exposed to clear sky conditions: (a) photo, (b) data.

The FTIR reflectance spectrum of the metallic sample after 1 month of air exposure was measured and it is reported in Figure 11, compared to as grown one. A degradation phenomenon that reduces emission performances in the transparent atmosphere window is evident. In particular, a decrease of $\mathrm{TO}$ and LO Si-N and Si-O absorption modes is present. 
a)

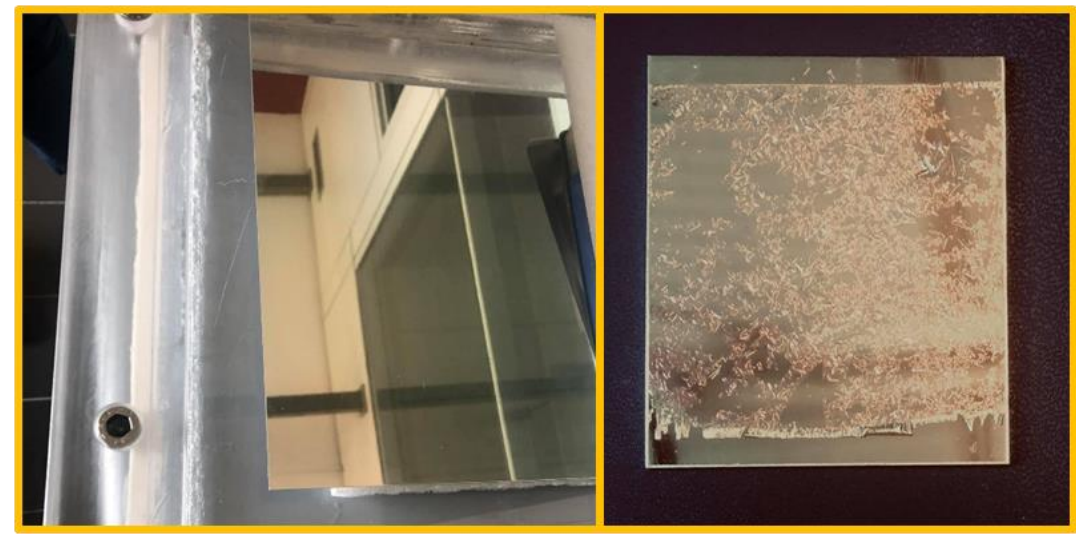

b)

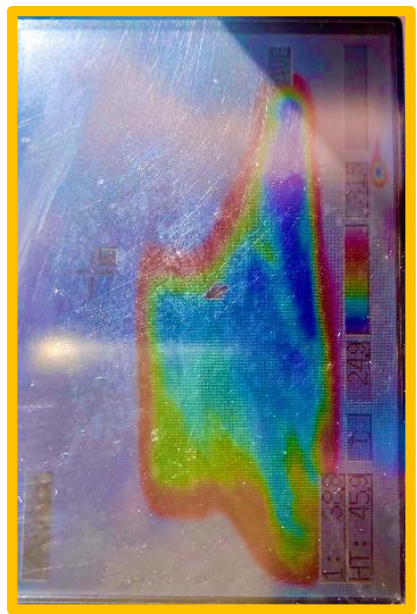

Figure 10. (a) Photos of mirror coatings before and after test. (b) ThermoCamera image during test.

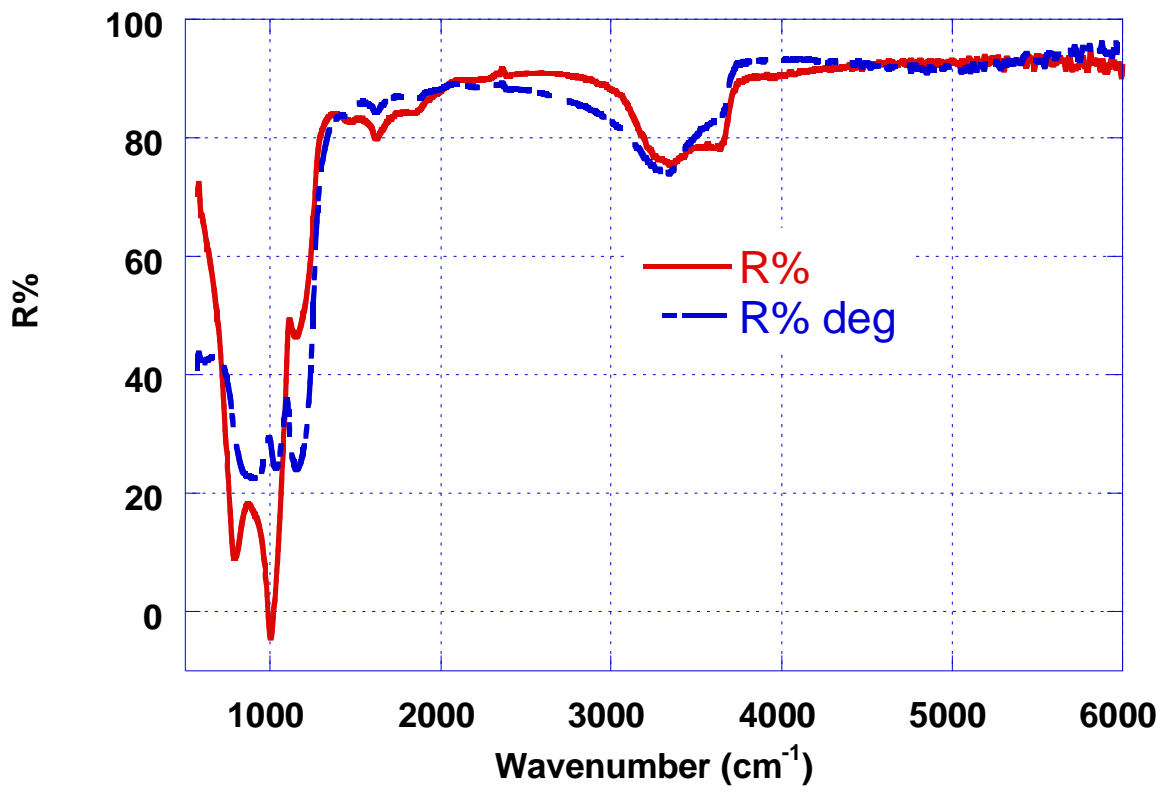

Figure 11. FTIR Reflectance before the field test and after 1 month. 


\section{Discussion}

Aims of this work is the proof of concept of a passive daytime radiative cooling device, to be potentially integrated with a chiller or a fan coil (and in such case semi-passive) to maintain cool an indoor environment reducing electricity consumption. This electricity saving can be achieved if the cooler located on the roof is able to grant, under direct sunlight, a temperature well below ambient temperature.

In a classical macroscopic physics approach, a radiative cooler exposed to a daylight sky is subject to both global solar irradiance and atmosphere thermal radiation. The net cooling power emitted by the radiator depends on the power balance between radiative, convective, and conductive transport phenomena. In particular, the device radiative power has to increase, while the conductive and convective parts have to lower. The radiative device power can be maximized with the use of emissive materials (that strongly emit in the window transparency window of 8-13 micron range). The amount of the incidental atmospheric radiation $\left(P_{\text {sunAM1.5 }}\right)$, which is absorbed by the radiator, can be diminished by increasing reflectance in solar range $(250-2500 \mathrm{~nm})$. The power absorbed by the surrounding atmosphere $\left(P_{a t m}\right)$ and the power gained due to convective and conductive phenomena $\left(P_{\text {conv }+c o n d}\right)$, which could heat the device can be lowered by means of a proper insulation from ambient.

When the radiated output power exceeds the net absorbed power $\left(P_{\text {sunAM1.5 }}+P_{\text {atm }}+P_{\text {conv }+ \text { cond }}\right)$, the radiator temperature lowers.

Thus, to achieve a state where $T$ is significantly below $T_{a}$, an engineered material with peculiar optical properties has to be integrated in a device where the radiative emission within the $8-13 \mu \mathrm{m}$ wavelength region has to be maximized and the absorbed power from the incoming atmospheric radiation, non-radiative contributions, and absorption of solar power must be minimized. All these requirements can be satisfied acting on the different constituents of the cooling device, in particular tailoring optical properties of engineered metamaterial.

The global AM1.5 solar spectrum in the Mediterranean area has an irradiance value of about $1000 \mathrm{~W} / \mathrm{m}^{2}$ and a significant absorption of this power flux can easily diminish the cooling effect of the device. For this reason, the passive radiative coolers reported in the literature are utilized in the night. For a daytime application, it is important that solar incoming radiation is highly reflected $(95 \%)$ in all spectral wavelength range, except for the $8-13$ micron window $\left(770-1250 \mathrm{~cm}^{-1}\right)$, where a strong selective emission is required. In case of a lack of selectivity in such IR region, a significant absorption of the atmospheric radiation outside the transparency window can occur, not allowing the cooling device to achieve temperatures significantly below the ambient temperature.

Moreover, certain atmospheric conditions can significantly influence the cooling potential, reducing the transmittance window. Particularly, the parameter mostly affecting the cooling potential is the atmospheric humidity: in a cloudy sky, the atmosphere can be completely opaque to IR radiation, invalidating any beneficial effect of the cooling device.

Within the present work, a demonstrative experiment has been performed on a proprietary prototypal device, as proof of concept of daytime passive radiative cooler properties of engineered metamaterials that exposed to direct solar irradiation, can stay well below ambient temperature.

The engineered metamaterial has been fabricated by means of a low cost, scalable sputtering process starting from cheap and abundant materials

For achieving high emissivity, silicon oxides, and nitrides have been included in the chemical composition of the materials, fabricated in form of thin films, and characterized in the full wavelength range, to validate the simulations in a region where commercial database have a lack of data. Moreover, the choice of amorphous oxides and nitrides of a same element (e.g., silicon oxide and nitrides, aluminum oxide and nitrides), was also based on the quantum tunneling of phonon dispersion heat transfer in the Heisenberg picture (the closest picture of condensed matter physics to the classical macroscopic physics [34]), where vibrational excitations can tunnel, quantum-like, from one lattice to another similar, if they are positioned at nanometer distance (e.g., in contiguous layers of the metamaterial). 
Clearly, once defined the desired sequence of layers, it is necessary to optimize a sequential sputtering process. It typically suffers from modifications of ideal layer deposition conditions (e.g., substrate temperature increase) that can modify selected ideal process parameters. Moreover, chemical compatibility of different materials in contiguous layers (as coming from optical simulation and heat transfer considerations) is the real challenge of metamaterial realization. For example, plasma oxygen can be dangerous for the silver layer, so that contiguous layers cannot be oxides. Reticular mismatch from a layer to another can cause tensile or compressive stresses that compromise adhesion, or metamaterial mechanical stability. The process optimization is specific for every substrate and for every thickness of each single layer constituting the coating. Furthermore the process optimization is different depending on the thickness of the layers (thin $(>100 \mathrm{~nm})$ and ultrathin $(<15 \mathrm{~nm})$ layers), which do not have bulk properties as those simulated. As an example, in the present work, based on mechanical and thermal considerations, a metallic substrate was selected to build the device, but a silicon substrate (as in the work of Raman [24]) would have provided a better adhesion between the materials constituting the coating. In this regard, a better adhesion on aluminum will be the objective of a future revised prototype. Most probably the first adaptive layer is too thin (only $10 \mathrm{~nm}$ ), causing mechanical stresses due to mismatching of reticular structures. A way to overcome this problem is to heat the substrate before layers deposition. Another potential cause of delamination is the formation of ammonium ions; which, in form of gas, bubble out from the metamaterial, since in the selected testing conditions AlN can hydrolyze. Similar consideration can be applied to Tungsten adaptive layer, which could be oxidized, forming tungsten oxides (explaining the pink color of delaminated parts).

Concerning the device, as well described in the previous section, a greenhouse effect inside the prototype case was detected, due to the absence of proper lateral sunshades. Despite such initial difficulty, the CM plate has demonstrated to be able to reach a temperature well below the ambient one, showing reproducible behavior also when tested in comparison with its only substrate.

Based on the evidences acquired from this proof of concept, the future work will be devoted to optimize the prototype, to newly test it using the same promising engineered cool metamaterial, and to apply it as platform for material testing on the field. As a future step, the system will be equipped with lateral sunshades and subsequently tested under direct sun irradiation. At the same time, considering that $\mathrm{CMs}$ are very interesting materials also when exposed directly to air, additional work will be devoted to optimize formulations for materials to be directly used in radiative roofing, further improving their optical properties and facing the issue of adhesion on different substrates and performance stability in air.

In summary, within the present work, the development and testing of a new prototype of daytime radiative cooler device, that can be used to mirror solar radiation and to emit heat in dark cool sky through atmospheric window, was performed, achieving promising results in terms of cooling efficacy $\left(-12{ }^{\circ} \mathrm{C}\right.$ registered under the experimental conditions tested). A cross-disciplinary approach in the development of $\mathrm{CM}$ and device is expected to be the key factor in view of the deployment of this promising technology.

\section{Conclusions}

Within the present work, a prototype of daytime passive radiative cooler has been developed and tested during daytime, starting from an engineered metamaterial formulation (named CM) by means of photonic approach method combined to a low cost scalable sputtering deposition process, passing through the manufacturing of a rectangular box device. Promising results have been obtained for the $\mathrm{CM}$ surface, which has reached a steady state temperature well below the ambient temperature $\left(-12{ }^{\circ} \mathrm{C}\right)$ under direct sunlight. The whole process of design, fabrication, characterization of the $\mathrm{CM}$ and the testing on field of the device are described. However, some design limitation are identified, both for the CM and for the device, such as coating stability on some substrates (e.g., aluminum) and the absence of sunshades on the lateral wall of the device. 
The obtained experimental evidences will be fundamental in driving the future research activities for the development of new metamaterials and new devices, following a cross disciplinary approach at material/system level.

\section{Patents}

Starting from the results here reported work is in progress to rethink a metamaterial formulation able to control electromagnetic and optic waves in order to radiate excess of heat out of the space, being at the same time stable on different construction substrates as a smart tailorable skin.

Author Contributions: A.C.: conceptualization, methodology, investigation, data analysis, original draft preparation, writing-reviewing-editing. G.V.: prototype project and development, investigation, figure and photos curation. E.G.: optical filter project definition, sputtering process optimization, data analysis, writing. M.F.: conceptualization, semi-empirical optical filter simulation, sputtering deposition on a pre-industrial plant, data analysis, writing. M.L.: funding acquisition, supervision, writing-reviewing. M.Z. investigation, writing-rewriting, supervision. All authors agreed to the published version of the manuscript.

Funding: This research was funded by MISE, Italian Ministry of Economic Development within the Programme 2019-2021, "Ricerca di Sistema Elettrico".

Acknowledgments: In this section, we would like to acknowledge Alessandro Antonaia for introducing us to this research topic and helping us with Figure 3, before his retirement, and Angelo Merola for thermocamera images acquisition.

Conflicts of Interest: The authors declare no conflict of interest.

\section{References}

1. Pachauri, R.K.; Allen, M.R.; Barros, V.R.; Broome, J.; Cramer, W.; Christ, R.; Church, J.A.; Clarke, L.; Dahe, Q.; Dasgupta, P.; et al. Climate Change 2014: Synthesis Report. Contribution of Working Groups I, II and III to the Fifth Assessment Report of the Intergovernmental Panel on Climate Change; Pachauri, R.K., Meyer, L.A., Eds.; IPCC: Geneva, Switzerland, 2014; p. 151. Available online: https://www.ipcc.ch/report/ar5/syr/ (accessed on 12 August 2020).

2. Rosenzweig, C.; Solecki, W.; Hammer, S.A.; Mehrotra, S. Cities lead the way in climate change action. Nature 2010, 11, 467-909. [CrossRef] [PubMed]

3. Arnfield, A.J. Two decades of urban climate research: A review of turbulence, exchanges of energy and water, and the urban heat island. Int. J. Climatol. 2003, 23, 1-26. [CrossRef]

4. Oke, T.R. City size and the urban heat island. Atmos. Environ. 1973, 7, 769-779. [CrossRef]

5. EIA Report 2019: International Energy Outlook 2019 with Projections to 2050 U.S. Energy Information Administration (EIA). Available online: https://www.eia.gov/ieo (accessed on 12 August 2020).

6. Wenz, L.; Levermanna, A.; Auffhammere, M. North-south polarization of European electricity consumption under future warming. Proc. Natl. Acad. Sci. USA 2017, 114, E7910-E7918. [CrossRef] [PubMed]

7. Santamouris, M.; Kolokotsa, D. On the impact of urban overheating and extreme climatic conditions on housing, energy, comfort and environmental quality of vulnerable population in Europe. Energy Build. 2015, 98, 125-133. [CrossRef]

8. Santamouris, M. Cooling the cities-A review of reflective and green roof mitigation technologies to fight heat island and improve comfort in urban environments. Solar Energy 2014, 103, 682-703. [CrossRef]

9. O'Malley, C.; Piroozfar, P.; Farr, E.R.; Pomponi, F. Urban Heat Island (UHI) mitigating strategies: A case-based comparative analysis. Sustain. Cities Soc. 2015, 19, 222-235. [CrossRef]

10. Konopacki, S.; Akbari, H.; Pomerantz, M.; Gabersek, S.; Gartland, L. Cooling Energy Savings Potential of Light-Colored Roofs for Residential and Commercial Buildings in 11 U.S. Metropolitan Areas; Lawrence Berkeley National Laboratory: Berkeley, CA, USA, 1997. Available online: https://www.epa.gov/sites/production/files/ 201408/documents/coolingenergysavingspotentialoflightcoloredroofs.pdf (accessed on 12 August 2020).

11. Baniassadi, A.; Sailor, D.J.; Crank, P.J.; Ban-Weiss, G.A. Direct and indirect effects of high-albedo roofs on energy consumption and thermal comfort of residential buildings. Energy Build. 2018, 178, 71-83. [CrossRef]

12. Levinson, R.; Berdahl, P.; Akbari, H. Solar spectral optical properties of pigments-Part I: Model for deriving scattering and absorption coefficients from transmittance and reflectance measurements. Sol. Energy Mater. Sol. Cells 2005, 89, 319-349. [CrossRef] 
13. Berdahl, P.; Chen, S.S.; Destaillats, H.; Kirchstetter, T.W.; Levinson, R.; Zalich, A.M. Fluorescent cooling of objects exposed to sunlight-The ruby example. Sol. Energy Mater. Sol. Cells 2016, 157, 312-317. [CrossRef]

14. Karlessi, T.; Santamouris, M.; Apostolakis, K.; Synnefa, A.; Livada, I. Development and testing of thermochromic coatings for buildings and urban structures. Sol. Energy 2019, 83, 538-551. [CrossRef]

15. Baniassadi, A.; Sailor, D.J.; Ban-Weiss, G.A. Potential energy and climate benefits of super-cool materials as a rooftop strategy. Urban Clim. 2019, 29, 100495. [CrossRef]

16. Givoni, B. Solar heating and night radiation cooling by a roof radiation trap. Energ. Build. 1977, 1, 141-145. [CrossRef]

17. Lu, X.; Xu, P.; Wang, H.; Yanj, T.; Hou, J. Cooling potential and applications prospects of passive radiative cooling in buildings: The current state-of-the-art. Renew. Sustain. Energy Rev. 2016, 65, 1079-1097. [CrossRef]

18. Liu, C.-H.; Ay, C.; Tsai, C.-Y.; Lee, M.-T. The Application of Passive Radiative Cooling in Greenhouses. Sustainability 2019, 11, 6703. [CrossRef]

19. Hossain, M.M.; Gu, M. Radiative Cooling: Principles, Progress, and Potentials. Adv. Sci. 2016, 3, 1500360. [CrossRef] [PubMed]

20. Gentle, A.R.; Smith, G.B. “A subambient open roof surface under the mid summer sun”. Adv. Sci. 2015, 2, 1500119. [CrossRef]

21. Rephaeli, E.; Raman, A.; Fan, S. Ultra broadband photonic structures to achieve high-performance daytime radiative cooling. Nano Lett. 2013, 13, 1457-1461. [CrossRef]

22. Pendry, J.B.; Schurig, D.; Smith, D.R. Controlling Electromagnetic fields. Science 2006, 312, 1780-1782. [CrossRef]

23. Liu, Y.; Zhang, X. Metamaterials: A new frontier of science and technology. Chem. Soc. Rev 2011, 5, $2494-2507$. [CrossRef]

24. Hossain, M.M.; Jia, B.; Gu, M. A Metamaterial Emitter for Highly Efficient Radiative Cooling. Adv. Opt. Mater. 2015. [CrossRef]

25. Ko, B.; Lee, D.; Badloe, T.; Rho, J. Metamaterial-Based Radiative Cooling: Towards Energy-Free All-Day Cooling. Energies 2019, 12, 89. [CrossRef]

26. Fu, Y.; Yang, J.; Su, Y.; Du, W.; Ma, Y. Daytime passive radiative cooler using porous alumina. Sol. Energy Mater. Sol. Cells 2019, 191, 50-54. [CrossRef]

27. Lim, X.Z. The Supercool Materials That Send Heat to Space. Nature 2020, 577, 18-20. [CrossRef]

28. Kong, A.; Cai, B.; Shi, P.; Yuan, X.C. Ultra-broadband all-dielectric metamaterial thermal emitter for passive radiative cooling. Opt. Express. 2019, 27, 30102-30115. [CrossRef]

29. Zhai, Y.; Ma, Y.; David, S.N. Scalable-manufactured randomized glass-polymer hybrid metamaterial for daytime radiative cooling. Science 2017, 355, 1062-1066. [CrossRef]

30. Esposito, S.; D’Angelo, A.; Antonaia, A.; Castaldo, A.; Ferrara, M.; Addonizio, M.L.; Guglielmo, A. Optimization procedure and fabrication of highly efficient and thermally stable solar coating for receiver operating at high temperature. Sol. Energy Mater. Sol. Cells 2016, 157, 429-437. [CrossRef]

31. Castaldo, A.; Ferrara, M.; Antonaia, A. Low emissive sputtered coating for smart glazing. In Proceedings of the IEEE: 18th Italian National Conference on Photonic Technologies (Fotonica 2016), Rome, Italy, 6-8 June 2016; IET: London, UK, 2016; pp. 1-4. [CrossRef]

32. Antonaia, A.; Addonizio, M.L.; Esposito, S.; Ferrara, M.; Castaldo, A.; Guglielmo, A.; D’Angelo, A. Adhesion and structural stability enhancement for Ag layers deposited on steel in selective solar coatings technology. Surf. Coat. Technol. 2014, 255, 96-101. [CrossRef]

33. Ferrara, M.; Castaldo, A.; Esposito, S.; D'Angelo, A.; Guglielmo, A.; Antonaia, A. AlN-Ag based low-emission sputtered coatings for high visible transmittance window. Surf. Coat. Technol. 2016, 295, 2-7. [CrossRef]

34. Chiloyan, V.; Garg, J.; Esfarjani, K.; Chen, G. Transition from near-field thermal radiation to phonon heat conduction at sub-nanometre gaps. Nat. Commun. 2015, 6, 6755. [CrossRef]

(C) 2020 by the authors. Licensee MDPI, Basel, Switzerland. This article is an open access article distributed under the terms and conditions of the Creative Commons Attribution (CC BY) license (http://creativecommons.org/licenses/by/4.0/). 